\title{
¿En estos momentos es necesaria la religión? Un ejercicio pedagógico con estudiantes de cultura teológica"
}

\author{
Alvaro Hernández Acevedo**
}

Recibido: 24 de mayo de 2016 • Aprobado: 31 de julio de 2016

\section{Resumen}

En este artículo, fruto de un trabajo de investigación en el aula, con estudiantes de Ingeniería Civil, ingeniería Mecánica, Arquitectura, Contaduría y Derecho, se intenta presentar las argumentaciones que surgen de la necesidad de la religión en la vida actual de la sociedad. Se parte de una indagación realizada por medio de encuestas libres sobre la visión de si percibimos una crisis religiosa en la sociedad, la necesidad de la religión en el mundo de hoy, y su papel en la búsqueda de soluciones a las grandes problemáticas que afronta la sociedad y el entorno humanos. Posteriormente se encontraron algunas categorías como desconocimiento del concepto religión, religiosidad y espiritualidad, tradicionalismos, indiferencia ante lo religioso; en esa medida, surgió una confrontación con los aportes teóricos venidos de la teología, la filosofía de la religión y el aporte de las demás ciencias. La

Se presenta este artículo como fruto de un trabajo de práctica pedagógica con estudiantes de Cultura Teológica de diferentes carreras profesionales de la Universidad Santo Tomás y como parte de un proyecto de investigación parcial denominado "Formación de ciudadanos como proceso integral, transversal e incluyente de los jóvenes de bachillerato y el aporte formativo de la educación superior en la ciudad de Tunja" que indagó la necesidad de la religión y su relación con la formación de ciudadanos, para preparar los instrumentos de investigación. Este artículo hace de la línea Humanismo y Educación del grupo Expedicionarios Humanistas.

* Licenciado en Filosofía Pura de la Universidad Santo Tomás, Teólogo del Convento Santo Domingo Especialista en Pedagogía para la Educación Superior, Universidad Santo Tomás, Villavicencio. Maestrante en Pedagogía, Universidad Santo Tomás, Tunja. Correo: alvaro.hernadez@usantoto.edu.co. 
importancia de este ejercicio académico no sólo fue la generación de conocimiento a partir de la experiencia de los estudiantes, sino la aplicación concreta de un método de investigación, lo cual enriqueció la cátedra de Cultura Teológica y la apreciación que tienen a propósito de las humanidades.

Palabras clave: Cultura teológica, religión, religiosidad, humanidades, práctica pedagógica.

\title{
Is religion necessary in these moments? \\ A pedagogical exercise with students of theological culture
}

\begin{abstract}
In this article, the result of a research work in the classroom with students of Civil Engineering, Mechanical Engineering, Architecture, Accounting and Law, we try to present the arguments that arise from the need for religion in modern life of society. It is part of an inquiry conducted through free surveys vision if we perceive a religious crisis in society, the need for religion in the world today, and its role in finding solutions to the major problems facing the society and the human environment. Subsequently, some categories as ignorance of the concept religion, religiosity and spirituality, traditionalism, religious indifference found; to that extent, a confrontation with the theoretical contributions come from theology, philosophy of religion and the contribution of other sciences emerged. The importance of this academic year was not only the generation of knowledge from the experience of students, but the practical application of a research method, which enriched the chair of Theological Culture and appreciation with about humanities.
\end{abstract}

Key words: Theological culture, religion, religiosity, humanities, pedagogical practice.

\section{La religion est-elle nécessaire en ce moment? \\ Exercice pédagogique avec des étudiants en culture théologique}

\section{Résumé}

Dans cet article, fruit d'un travail de recherche réalisé en classe avec des étudiants en ingénierie civile, ingénierie mécanique, architecture, comptabilité et droit, on essaye de présenter 
les arguments qui surgissent du besoin de la religion dans la vie actuelle de la société. On part d'une recherche réalisée à travers d'enquêtes libres au sujet de s'il l'on perçoit une crise religieuse dans la société, le besoin de la religion dans le monde actuel, et son rôle dans la recherche de solutions aux grandes problématiques qu'affronte la société et les êtres humains. Par la suite, on a trouvé quelques catégories telles que l'ignorance du concept de religion, piété et spiritualité, traditionalismes, indifférence face à la religion; dans cette mesure, il a surgit une confrontation avec les apports théoriques venus de la théologie, la philosophie de la religion et la contribution des autres sciences. L'importance de cet exercice académique n'a pas seulement été la production de connaissance à partir de l'expérience des étudiants, mais aussi la mise en pratique concrète $d^{\prime}$ une méthode de recherche, qui a permis d'enrichir le cours de culture théologique et l'appréciation qu'ils ont sur les sciences humaines.

Mots clés: Culture théologique, religion, piété, sciences humaines, pratique pédagogique.

\section{Introducción}

En el inicio del semestre de la Cátedra institucional de Cultura Teológica, con el ánimo de buscar relaciones entre la literatura de lo religioso y lo teológico, se emprendió una tarea en conjunto con los estudiantes de indagar acerca de la necesidad de la religión en el mundo actual, de sus apreciaciones acerca del tema, y en otro orden, sirvió de motivación para que se interesaran por la generación de escritos y la misma investigación. En este texto, se describirán las experiencias obtenidas en el aula, el conocimiento que se construye en conjunto con los profesionales en formación y la guía del docente; después se presenta un diálogo de saberes de la mano de autores que han investigado esta temática, y por último, se establecerán algunos puntos de vista que iluminarán la problemática en cuestión. Esta pregunta problematizadora surgió después de un diálogo abierto en el que se intentaba descubrir cuáles fueron las primeras apreciaciones o prejuicios que comportaban lo que se podría definir como la conducta de entrada para iniciar el curso de Cultura Teológica.

En ese orden de ideas, a continuación se presentan algunas de las conclusiones de los estudiantes, donde se muestra el parecer y posible pertinencia de la religión en nuestros días.

Los estudiante de Ingeniería Mecánica afirmaron que: "actualmente se evidencia una real y verdadera crisis religiosa desde muchas perspectivas como la diversidad de religiones... además que se han convertido en medios de lucro, se ha corrompido la religión en casos como pedofilia y otros abusos, pero uno de los 
problemas más acuciantes es el uso de la fuerza para someter a la humanidad como es el Islam" (Mec. 1, 2016)․․ En los momentos actuales la sociedad está marcada por un individualismo que no permite analizar o resignificar las experiencias de injusticia, desigualdad y atentados contra la dignidad humana; ante estas vivencias se podría vivir mejor con los ojos cerrados, y de hecho, se nota que es lo mejor cuando no se ve afectado de manera directa. En este sentido, la religión ha perdido o pervertido su dimensión profética ante el entorno social, y se rige bajo los principios de la eficacia, la productividad y el consumismo capitalista. "Actualmente se ha escuchado de un problema mundial que es el autodenominado Estado Islámico, que ha corrompido el "original" Islam (las comillas son del autor), añadiendo normas que atentan contra la humanidad con la justificación de honrar a su Dios. Esta situación, vista desde la ingeniería, afecta, en casos como los pozos petroleros, pues en manos de este grupo, a la economía mundial" (Mec. 2. 2016).

Los estudiantes de derecho, por su parte, dijeron que: “En la actualidad se evidencia un cierto respeto por las creencias de cada persona, pero es más un aislamiento, indiferencia y rechazo al disenso para evitar tanto el compromiso por lo que se piensa, siente y decide, como la confrontación con el otro". De esta manera, es notorio el hecho que haya una separación entre vida de fe y vida cotidiana, y la religión ya no comporta un ordenamiento moral, pues surgen otros fundamentos de orden racional o social que cumplen la misma función (Der. 1, 2016) $)^{2}$. "También es sintomático que la juventud experimente una crisis existencial de sentido que se manifiesta en el afán desmedido de consumo hasta el punto de medir las relaciones por el materialismo y grado de uso (abuso) de la tecnología, dejando a un lado la historia que, a pesar de todo, va construyendo". Además, la religión no puede seguirse convirtiendo en un medio de lucro ni que utilice la violencia como medio de conversión, pues estos fenómenos corrompen los fundamentos de la religión" (Der. 2, 2016).

\section{¿La religión aporta soluciones a la problemática actual?}

En estos tiempos y en ciertos ambientes sociales, es posible hablar de un mundo sin religión, de una fe universal pero personal, donde prevalezca lo antropológico sobre lo teológico y sobre todo, que permita el encuentro consigo mismo. Gracias

1 Reflexión de grupos de ingeniería mecánica en el aula el 4 de febrero de 2016.

2 Reflexión de grupos de derecho en el aula el 4 de febrero de 2016. 
al exagerado intimismo del ser humano y, por el hiperconsumismo, el hombre puede llegar a comprender que su imagen de Dios la puede hacer a su medida y estado de confort. De aquí se entiende la afirmación de un grupo de Derecho: “La religión debe volver a la persona en su totalidad para experimentar su esencia que no es otra cosa que paz interior, pero la actual versión de la religión es signo de un total alejamiento de la esencia de la religión, pues cada uno siente lo que quiere y no debe interceder en la vida social de los seres humanos." (Der. 2, 2016)

En otro paso de nuestro proceso de investigación, los estudiantes debían hacer las mismas preguntas que se desarrollaron en el aula, a diferentes personas, y en otra sesión de clase se diseñó una matriz de evaluación, en la cual se obtuvieron algunas categorías nuevas que se contrastaron con los referentes teóricos que se han venido trabajando.

En ellas se obtuvieron, además, algunas conclusiones que sustentan la necesidad de seguir en el proceso de investigación acerca del papel de la religión en la vida actual de la sociedad; teniendo en cuenta dimensiones como lo económico, lo social, el testimonio de vida de los creyentes y profesionales de la fe, y lo cultural. Así pues, el papel de la iglesia en la cotidianidad del mundo de la vida está replegado a ciertos espacios y lugares donde se expresa la religiosidad. Así lo atestiguan varias apreciaciones, tanto de los estudiantes como de las personas que fueron encuestadas. Por ejemplo, un grupo de contaduría concluyó lo siguiente: "la Iglesia debe ser agente de testimonio de esperanza, que promueva la importancia de creer como adhesión existencial del ser humano a un Dios, debe recuperar en la mentalidad de los fieles el sentido de la Tradición, e invitar a cada creyente a un verdadero acercamiento a la Palabra de Dios" (Cont. 1, 2016).

En esta misma línea aporta otro grupo de Contaduría:

En la dinámica de la vida cotidiana, la religión no tiene ninguna relevancia ni influencia, puesto que se denota en la sociedad una marcada indiferencia ante la expresión religiosa, pues ya se asume que pertenece a la vida privada del ciudadano. La Iglesia como institución ha aportado que este tipo de actitudes se haya acrecentado, en vista que sus ministros en sus predicas, opiniones critican lo que sucede en la sociedad, pero no participan de todo el diario vivir de los individuos, creyentes o no, incluso evidencia una falta de coherencia entre los valores que predican y las acciones que llevan a cabo. Algunos entienden la fe y sus sacramentos como simples expresiones o eventos sociales. Es importante el mensaje que nace de una fe, pero no tiene una incidencia radical en la vida cotidiana". En últimas, en estos tiempos actuales no 
se necesita de religión, sino de una espiritualidad profunda, coherente

y vinculante de todo acontecimiento del ser humano" (Cont. 2, 2016) ${ }^{3}$

Un grupo de ingeniería civil concluyó después de este ejercicio en clase que "se deben generar estrategias, mecanismos y políticas a nivel regional, nacional e internacional en orden de trabajo, posibilidades de acceso al estudio y regulaciones en cuanto al cuidado del medio ambiente, porque sólo así se podrá transformar una sociedad igualitaria, incluyente y tolerante. Este es uno de los papeles que la iglesia ministerial, en fin, la iglesia toda, podrá aportar, y así su mensaje, testimonio y estilo de vida servirán de ejemplo ante los nuevos valores que quiere imponer esta sociedad tecnocrática y consumista" (Civil b 1, 2016).

\section{Indiferencia religiosa}

La referencia existencial, personal y social, ante lo divino, ha venido tomando diversas comprensiones con distintos matices, en el que algunos afirman que el único canal de supervivencia de la religiosidad se encuentra en la presentación de contenidos religiosos evolutivos y polifacéticos, ya que cualquier clase de desarrollo dogmático tradicional, va a conducir a la petrificación religiosa y a su anacronismo (Poupard, s.f.); pero existe la posibilidad que se presenten nuevas y serias respuestas que la modernidad no ha podido brindar a ese ser humano que grita cuestionamientos que le darían sentido a su existencia plena. Así lo expresa un grupo de estudiantes: "Es difícil creer que la religión solucione un problema social, porque se ha corrompido tanto que ahora todo es lucro, pero desde una perspectiva más profunda, aportaría más hacia un campo personal, de estar en paz consigo mismo, y ese equilibrio es la base de toda paz en la familia y en la sociedad" (Mec. 1, 2016).

En los tiempos actuales, hay un descontento en un gran porcentaje de la humanidad por lo religioso, pues desde lo racional, no encaja. Ante ello, existen protestas y rechazo directo, pero en una gran mayoría de este porcentaje, simplemente han entrado en indiferencia. Esta actitud es consecuencia de un subjetivismo y un relativismo generalizado de la sociedad que rechaza toda tendencia totalizante y absolutista, en vista que la verdad pasó al estadio de la interpretación y de la conciencia que está por encima de la norma (Vian, 2009, p. 230). Este

3 Postura de un grupo de estudiantes de Contaduría nocturna del día 04 de febrero de 2016, quienes asumen seriamente un diálogo entre su fe, el discurso de cultura teológica en su desempeño laboral. 
es un argumento importante del Papa Francisco, respondiéndole a Scalfari, pues el que no cree, debe obedecer a su propia conciencia, y en este particular se convierte en el eje de bondad o maldad de los actos (2013, p.5).

La indiferencia religiosa, por otro lado, es una actitud en la que el sujeto no tiene aceptación ni rechazo a Dios, solamente tiene un desinterés y desafección hacia él, está marcada por una tendencia a lo intrascendente, a la respuesta fácil ante lo que sucede en el diario vivir, gracias a que no existe mayor preocupación por aquellos interrogantes que enmarcarían el sentido de la existencia de lo humano que también incluye lo divino. Esta expresión de indiferencia religiosa va unida a un paradójico crecimiento de orientaciones diversas espirituales, religiosas y pseudoreligiosas en todo el mundo, según Paul Poupard (s.f.).

La vida religiosa de los jóvenes está marcada por un tradicionalismo infructuoso que no llena las expectativas de sus interrogantes, anhelos y perspectivas, pues han sido educados (entiéndase instruidos) en los rituales, creencias y actos de tradición religiosa que no les permiten formarse ellos mismos una vida en plenitud. Los estudiantes afirman que, una vez salían de las eucaristías o de los cultos, sentían que su vida continuaba de la misma manera, se sentían vacíos en su vida interior, sin generar un compromiso real y mucho menos sin un proceso de conversión, lo que ha generado que la vida de fe no tenga ninguna relevancia en la vida cotidiana (López M., 2015, p. 5).

\section{Indiferencia religiosa de carácter radical}

En este aparte nos referimos a la actitud de alejamiento, abstención y pérdida de sentido ante lo religioso y sus manifestaciones, en la cual se evidencia una confusión sobre la idea que se tiene de Dios, pues se le identifica con energía vital, fuerza superior, espíritu impersonal, destino o fatalidad; se denota en los estudiantes un conformismo superficial donde muchos acaban viviendo como si Dios no existiera o como si su existencia fuera de total irrelevancia, pues asumen que su "presencia" no afecta en nada a su proyecto de vida. Exista o no exista Dios, no tiene ningún valor en su vida y menos en su concepción intelectual, lo que ha generado que la realidad social esté fragmenta en una enorme dispersión de intereses, sobre todo cuando la experiencia religiosa entra como en una especie de mercado entre todas las religiones e ideologías, a pesar de existir un clima de respeto y tolerancia. Así lo manifiesta Poupard:

La opción religiosa o de creyente es asunto meramente subjetivo, de elección personal, cuyos efectos son también subjetivos y objetivamente 
en nada distintos de los que un no creyente experimenta. No hay diferencia entre creer y no creer. La creencia de fe no aporta ningún beneficio o privilegio objetivo, cualquier clase de razonamiento que intente mostrar que la fe da respuestas a lo que el no creyente no tiene, se ve observado como anticuado, iluso y autoritario. Esta situación proviene de la aceptación legal en que los no creyentes poseen valores propios, dignos de respeto e iguales a los cristianos (Paul Poupard, s.f.).

\section{Indiferencia religiosa por descomposición}

Tomar de la religión y la norma moral, como mejor parece, es lo que ha generado ese sincretismo de religiones, pseudoreligiones y expresiones religiosas. Así, cualquier expresión radical de la fe es vista como sectaria, se vuelve rareza, y la afirmación sin ambages de identidad católica es criticada como fundamentalismo, del mismo modo que la pertenencia a una experiencia comunitaria eclesial se denuncia como integrismo o gueto. $\mathrm{Y}$ esto, no por las demás religiones, sino por los mismos católicos que, a fuerza de contemporizar con el secularismo, ha generado una propuesta católica "light" (Poupard, s.f).

Entonces, ¿será que la insatisfacción de la experiencia religiosa de la fe católica en nuestras sociedades, es el resultado de una vivencia intensa de la fe, descubierta como fraude? ¿No será más bien el rechazo a formas ingenuas, corrompidas y superficiales de una religiosidad popular "light", de moralismo legalista e ignorancia histórica? ¿La indiferencia no estará invocando de alguna manera una forma más radical de experiencia del Trascendente precisamente en la historia y una vivencia más intensa y personal de la vida comunitaria? Estas preguntas y demás que están en la mente de los estudiantes curiosos y "raros" por generar este tipo de cuestionamientos, son los que permitirán rescatar la imperiosa necesidad de buscar nuevas salidas comprometidas por la humanidad escindida del hombre de hoy. De esta forma, se evitará el riesgo de olvidar la identidad cristiana ante la confusión en las prácticas y la incoherencia de vida de los creyentes y ministros, porque será una vida creyente con compromiso y responsabilidad de vivir bajo los criterios y principios del Mensaje de Jesús, el Reino de Dios. 


\section{En realidad estamos en crisis}

No hay una explicación última para determinar el origen de la crisis religiosa, y en el parecer de José María Castillo está dada por “la degeneración moral y de los pecados, de los que tanto suelen hablar no pocos profesionales del sermón y de la práctica religiosa en general" (2012, p. 41); la cultura laicista, relativizada y secularizada son fenómenos sociales que, felizmente, han definido la autonomía de las ciencias y del sentido de la fe en el mundo actual, aunque también se evidencia la perversión de los valores absolutos debido al afán incontrolado de la ciencia y la tecnología.

Citando a Juan Martín Velasco (2010), Castillo trae a colación que la crisis tiene su origen en la forma falseada de presentar a Dios y de vivir la relación con él; la presentan los profesionales en esta área, de manera incomprensible, incoherente e insoportable. Lo predican como una realidad distinta y alejada de las realidades humanas, se puede relacionar con él, se le puede pedir, se le ofende como a un ser cualquiera.

Detrás de toda esta situación hay una pregunta fundamental: ¿Qué idea de

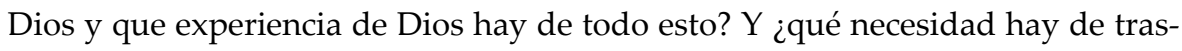
cendencia entonces? Es una realidad que, desde la prehistoria, el hombre ha cesado en la búsqueda de Dios, debido a nuestras carencias y deseos más humanos.

Respuestas, control, seguridad, miedo a la muerte, alteridad, sentido por la vida son algunas de las razones últimas y fundantes para seguir en el camino de búsqueda de Dios. J.M. Castillo ubica dos palabras de gran poder para comprender esa búsqueda y generación de imágenes o percepciones de Dios: el poder y la bondad (2012. P.43). Vistas así, la cosas ese Dios infinitamente poderoso y bueno es una imagen humana que nos hemos creado desde nuestra inmanencia, de la que no podemos salir.

La condición humana ha proyectado en Dios la imagen de un dios con poder y bondad sin límites, pero a la vez contradictorio y violento, porque no puede ser compatible tanto mal en el mundo con una visión de un dios infinitamente bueno. Se vive en una ambivalencia de lo sagrado por categorías como fascinans, tremens y numinoso, por las cuales se atrae y repele ante esa experiencia de lo sagrado. De ahí que también sea una constante la violencia dentro del mundo de lo religioso, por la confrontación experimentada del ser humano, además de la violencia religiosa con los no seguidores, aunque sí se predique una dignidad e igualdad para todos. Por lo tanto, "Dios es peligroso" (Beck, 2008).

Las tecnologías de la comunicación presentan una mezcla de todas las religiones, generando choques de universalismos, disputas sobre verdades reveladas y formas de satanizar a los demás, lo cual conlleva a "justificarse y a reflexionar 
tanto en la vida íntima como en los deberes públicos, allí donde antes dominaba la certeza" (Beck, 2009, p.62).

Es indudable la institucionalización de la religión, donde entran en escena los mediadores religiosos, es decir, los intermediarios entre Dios y los creyentes. Los sacerdotes, chamanes, presbíteros son considerados como representantes de la pureza y santidad ante la divinidad. En el pueblo de Israel también existió la mediación profética y sapiencial, generando una mayor libertad de pensamiento y capacidad autónoma de actuar por parte del pueblo. Ante esto los estudiantes expresan como conclusión que:

La religión se ha convertido en un negocio lucrativo y debe recordar el temor de Dios. La sociedad, que camina al lado, sin darse la mano, de las iglesias, se basa en el interés y la economía, lo que origina que la falta de dinero sea una de las causantes de violencia, acabando con la libertad o la vida de las demás personas por simple interés personal, a lo que la fe no influye en sus comportamientos ni le brinda razones para buscar el bien común ni la justicia del desconocido (Civil b 2, 2016).

Castillo afirma que en la iglesia católica se ha elaborado una teología del poder donde todo el poder mediador ha quedado concentrado en el sacerdocio, y el pueblo tiene que aceptar esto como elemento constitutivo de sus creencias hasta en lo más íntimo de la vida y la conciencia. Los poderes de los ministros quedaron consignados y legislados en "enseñar, santificar y gobernar" (LG 24-26). Y al pueblo fiel le corresponde obedecer.

\section{Alienaciones de la fe}

Este tema de las alienaciones de la fe surgió de varias discusiones entre los estudiantes y el docente. Se cuestionaron acerca de qué tan alienados estamos por las erradas comprensiones de la fe. Esto derivó hacia la tarea de realizar un trabajo corto de campo, en el que, siguiendo a José María Castillo (1978), se dividieron en grupos, se les asignó una de las alienaciones de la fe descritas por el autor (1978, p.65ss), y con base en ellas, debían redactar una problemática a "investigar"; después, redactarían cinco preguntas cerradas (de sí o no), con el fin de hacerlas a seis personas ( 3 estudiantes y 3 administrativos); hecha una corta tabulación de las respuestas, cada grupo obtuvo datos cuantitativos y conclusiones acerca de la comprensión de cada alienación. 
Cabe aclarar que no se puede obtener una información que cobre relevancia debido a la cantidad de preguntas y personas encuestadas, porque la intención última fue que los estudiantes aprendieran a hacer un trabajo de campo, integrando un ejercicio cualitativo y un enfoque cuantitativo.

Una vez que se caracterizó la indiferencia religiosa y las evidencias en el contexto inmediato, se llegó a la conclusión que la fe es una experiencia con la persona de Jesús y respuesta a su mensaje (Dei Verbum, nro.5), lo que implica una estructura dialogal de la fe en sentido cristiano (Latourelle, 1966, 467), y no una práctica sociológica de rituales o de sumisión cognitiva ante creencias marcadas por ese tradicionalismo al que nos hemos visto abocados a lo largo de la historia de la religiosidad cristiana; esto es lo que los teólogos definen como preámbulos de la fe, entre los que se encuentran la existencia de Dios, el valor de los principios fundamentales del ser, el existencial sobrenatural, la potencia obediencial, y las verdades mismas de la revelación divina (Castillo, 1978, p. 62).

En este sentido, se discutieron las alienaciones de la fe según Castillo (1978) y se dijo, respecto a la primera, que la fe, en muchas ocasiones, se ha reducido a la reducción de creer en un mensaje de salvación para la otra vida, porque la transformación del entorno según el mensaje cristiano no se ha hecho una realidad, y es vital que se lleve esa fe a este mundo, haciéndola útil para resignificarlo y transformarlo. He ahí una razón para tanta indiferencia religiosa. Además se denotó que las personas adultas asumen un papel más apegado al sentimiento religioso que los jóvenes, pues responden tajantemente que la fe es importante para establecer una relación de salvación; mientras que los jóvenes dejan a un lado la fe y la asumen como sin relevancia a la hora de pensar en una salvación.

Sobre la segunda alienación a la fe expresada por Castillo es "reducir la fe a un mensaje de santificación individual", pues si no se puede, o el desarrollo del mundo actual impide, que la fe genere cambios en lo público y en las relaciones políticas, económicas o sociales, esta fe se reduce al mundo de lo privado, y la experiencia incompleta del Cristianismo queda en un conjunto de virtudes privadas sin fuerza para influir en la vida pública de los pueblos y de la sociedad (1978, p. 67). Esta alienación es una respuesta a la indiferencia que se vive en la vida juvenil, porque no asumen su papel político, en el buen sentido de la expresión, de la fe, pues no afecta en nada su creencia o desafección ante lo religioso en su vida cotidiana. Es singular la apreciación que tienen los estudiantes respecto de esta alienación: “La religión sólo busca cómo programar a las personas para que cumplan un bien hacia algo que no existe, y por eso se vuelven locos" (opinión de una modelo de 21 años. Citado por Civil b 1, 2016). 
Según Castillo, la tercera alienación de la fe es la identificación de la fe con la práctica religiosa, es decir, si el creyente participa de todos los actos religiosos tiene una fe inquebrantable, porque la consideración de estos actos como sagrados es la pauta para "medir" la vida de fe. De ahí que los profesionales de este tipo de fe se convirtieran en los personajes más importantes de la vida religiosa y de la sociedad, encontrándose con Dios exclusivamente en los templos y lugares apartados del mundo. Esto generó en la historia que la vida cotidiana, lo político y el disfrute de la vida plena quedaran al margen de la fe, enseñando a las nuevas generaciones que no se experimenta a Dios en lo cotidiano, y peor aún, ubicándolo casi que en el horizonte de comprensión de una ideología que, quizás es importante porque, hay que creer en algo o alguien. Por eso, afirma Castillo que "la fe no sólo se expresa en la acción y el compromiso, sino también en la oración y en la celebración de los sacramentos" (1978, p. 69). Sin embargo, se debe asumir que estos últimos son símbolos humanos dialógicos entre la misión divina y la respuesta humana, dado que: "la iglesia primitiva no tuvo templos ni sacerdotes ni leyes rituales, pues los sacramentos se celebraban en las casas y el templo era la misma comunidad" (Cullman, 1948). A este respecto, los jóvenes sólo han conocido que la experiencia de su fe está enmarcada a espacios "sacados" de la vida cotidiana y en lugares donde sólo habita Dios, y como sus experiencias vitales han sido diferentes a estos lugares, se ha generado un rechazo y un alejamiento total a lo que pertenece a lo religioso.

Una cuarta alienación está relacionada con la identificación de la fe con la observancia legal (Castillo, 1978, p. 70). Esto quiere decir que se es más creyente cuanto más practique la ley divina, pero se olvida de la gran exigencia y mandato superior del amor y, por eso, no se ha enseñado a los jóvenes la vivencia de la libertad cristiana. Así, la juventud y el pueblo en general critica las acciones de los profesionales en la fe, porque se les ha instruido en la fe como ley, y al ver la humanidad que los limita, rechazan sus mensajes, sus prédicas, sus incoherencias, amen que no revisten de luz ni esperanzas para sus anhelos más profundos. Así lo ven los estudiantes: “Las personas no necesitan de la religión pues la ven como un negocio, representa corrupción y no como un medio para acercarse a Dios; su poder que muestra en la sociedad no está mediado por el servicio y el buen ejemplo, sino por actos arbitrarios". De ahí que no tenga un nivel de relevancia, porque cada persona piensa y cree en lo que quiera, ya que no tiene unos parámetros coherentes para dar razones de la fe que se predica desde las religiones, y a lo sumo que ha llegado es a generar actos de costumbre religiosa" (Civil b 3, 2016).

La quinta alienación es la reducción de la fe a una u otra forma de ascética (Castillo, 1978, p. 71), lo que quiere decir que, al privatizar la fe, cada persona 
asume el mensaje de Jesús como de sufrimiento, pietismo y pasividad, y que "más tarde" se vivirá el fruto de estas acciones. Se hace una lectura del mensaje de Jesús en esta clave, y no como la consecuencia de vivir bajo los valores del Reino de Dios que van en contra de todo aquello que atente contra la igualdad, libertad y justicia del ser humano. Es una realidad que mantener al pueblo fiel bajo estas premisas, resulta beneficioso para ciertos grupos dominantes a los que muchas veces la Iglesia ha alentado para su propio provecho, lo que le da razón a aquellos que entienden la religión como el opio del pueblo. Razón suficiente para mostrar una indiferencia ante la religión.

La sexta alienación es la reducción de la fe a una praxis socio-política que la asume como bandera de transformación de las condiciones sociales, políticas y económicas, lo cual estaría bien si no fuera excusa para derrocar los sistemas de poder para instaurar otro (Castillo, 1978, p. 72). Actualmente, pertenece a grupos minoritarios estas tendencias socio-políticas puesto que ya la religión ni siquiera cumple con las respuestas para intentar transformar el ritmo frenético de consumismo que también aliena y enajena la conciencia de la sociedad actual. Frente a esta alienación los estudiantes afirman que "la religión en estos momentos no es necesaria para la mayoría de los jóvenes, ya que no se les ha inculcado en su desarrollo personal” (Mec 1, 2016). "La religión no nos soluciona problemas, y las que creen se aferran es para buscar una solución precisamente, pero yerran en su intención a la hora de comprender la función de la religión” (Mec 2, 2016). “Cuando las personas están bien, no sienten necesidad de acercarse a Dios. Cuando se están pasando necesidades de salud, dinero o cualquier otra, se acude a ese Dios, y así sentir seguridad y paz interior" (Mec 2, 2016).

\section{Crisis actual de la fe en Dios}

No hay una explicación última para determinar el origen de la crisis religiosa, y al parecer de Castillo (1978) está dada por "la degeneración moral y de los pecados, de los que tanto suelen hablar no pocos profesionales del sermón y de la práctica religiosa en general" (2012, p. 41); la cultura laicista, relativizada y secularizada son fenómenos sociales que, felizmente, han definido la autonomía de las ciencias y del sentido de la fe en el mundo actual, aunque también se evidencia la perversión de los valores absolutos debido al afán incontrolado de la ciencia y la tecnología.

Citando a Juan Martín Velasco (2010), Castillo trae a colación que la crisis tiene su origen en la forma falseada de presentar a Dios y de vivir la relación con él; la presentan los profesionales en esta área, de manera incomprensible, 
incoherente e insoportable. Predican a Dios como una realidad distinta y alejada de las realidades humanas, pero se puede relacionar con él, se le puede pedir, se le ofende como a un ser cualquiera.

Detrás de toda esta situación hay una pregunta fundamental: ¿Qué idea de Dios y que experiencia de Dios hay de todo esto? Y ¿qué necesidad hay de trascendencia entonces? Es una realidad que, desde la prehistoria, el hombre ha cesado en la búsqueda de Dios, debido a nuestras carencias y deseos más humanos.

Búsqueda de respuestas, control, seguridad, miedo a la muerte, alteridad, sentido por la vida son algunas de las razones últimas y fundantes para seguir en el camino de búsqueda de Dios. Castillo ubica dos palabras de gran poder para comprender esa búsqueda y generación de imágenes o percepciones de Dios: el poder y la bondad (2012. P.43). Vistas así, la cosas ese Dios infinitamente poderoso y bueno es una imagen humana que nos hemos creado desde nuestra inmanencia, de la que no podemos salir.

\section{Por una necesidad de volver a lo trascendente}

Es necesario volver la búsqueda responsable, seria y crítica de la relación íntima del hombre con la trascendencia en su historia inmanente, de tal forma que exprese lo que afirma Boff como transparencia (2002, p. 80), la cual se evidencia en un comportamiento coherente entre lo que piensa, siente, cree y anhela. Esta transparencia es una apuesta por vivir bajo los principios de la misma vida de Jesús, el Cristo, que fue un hombre como nosotros, murió en la Cruz e, insurgentemente, enseñó un proyecto de vida, personal y social, llamado el Reinado de Dios, espacio socio-histórico donde se experimenta el absolutamente Otro; por eso "al amar otro estás amando a Dios, pues el amor a Dios y el amor al prójimo son un mismo y único amor, un mismo y único movimiento" (Boff, 2002, p. 80).

Así, ese ser humano, que apuesta por una vida transparente, lo que significa poder ver en el otro a Dios naciendo de la profundidad de su corazón, según Boff $(2002,81)$, evidenciará que las últimas razones de la indiferencia religiosa obedecen a una falta de conocimiento de la esencia de la religión, a una lectura parcializada de los fenómenos religiosos o religiosidades, en cuanto que es lo que los profesionales de la fe defienden y establecen como lo más importante para "medir" un buen creyente; además, a la falta de compromiso con la propia forma humana de creer y relacionarse con la divinidad, ya que se han venido encontrando nuevas respuestas al deseo de control, seguridad, miedo a la muerte, alteridad y sentido por la vida, razones últimas y fundantes para seguir en el camino de la 
búsqueda de Dios (Castillo, 2012), pero que la religión institucionalizada no ha dado sentido ulterior, puesto que la imagen que se nos ha dado de Dios es tan irreconciliable con el devenir histórico de la sociedad.

La crisis religiosa y de fe en Dios en la actualidad, las cuales obedecen a múltiples causas de orden histórico, tecnológico, existencial, teológico y moral. A lo largo del decurso de la historia humana, una vez que se superó la teocracia medieval y se incursionó en el paradigma mecanicista científico, la experiencia religiosa se convirtió en una práctica privada, gracias a que valores como la autonomía, la libertad, el bien-estar y el progreso se convierten en el marco de comprensión antropológica de la modernidad. Además, la clase emergente burguesa e intelectual acrecentaron el secularismo debido a la sospecha y desencanto por la religión y todo fenómeno religioso, lo que implicó una necesidad de buscar nuevos fundamentos tales como la razón, el nihilismo, la dignidad humana, y no una frustrada religión, de tal forma que se pudiera responder de manera "eficiente" a las expectativas de la humanidad.

Existe un descontento en un gran porcentaje de la humanidad por lo religioso, pues desde lo racional, no encaja. Ante ello, existen protestas y rechazo directo, pero en una gran mayoría de este porcentaje, simplemente han entrado en indiferencia. Además, con el surgimiento del pensamiento posmoderno, las certezas han perdido vigor, la verdad objetiva es reemplazada por el relativismo y el subjetivismo, donde todo vale $\mathrm{y}$, como se ha mencionado anteriormente, la conciencia está por encima de la norma, de tal manera que se puede afirmar que es posible hablar de un mundo sin religión, de una fe universal pero personal, que prevalezca lo antropológico sobre lo teológico y sobre todo, que permita el encuentro consigo mismo (Hernández A, 2016).

En este sentido, en las sesiones de clase se siguió la lectura crítica de un texto de Leonardo Boff, "Tiempo de Trascendencia, el ser humano como un proyecto infinito" (2002), con el fin de que cada estudiante asumiera el aporte de este gran teólogo, lo aplicara en su contexto concreto, y pudiera construir en conjunto nuevo conocimiento. En este sentido, lo que sigue son las conclusiones que surgieron a lo largo de las discusiones con los estudiantes y los aportes del docente.

\section{Soluciones desde el aula}

La crisis de fe se irá solucionando en la medida en que tengamos una verdadera y plena experiencia con la trascendencia, lo cual se traduce en una vida transparente que testimonia una imagen de Dios que no es de castigo, venganza o 
sufrimiento, sino de reconocimiento de Dios en el otro y lo otro, como experiencia originaria con el Dios vivo, no el de la metafísica ni el de nuestras vanas y limitadas imágenes. Además, los tiempos actuales no admiten la comprensión de una verdad absoluta que no asume posibilidad de relaciones. Así mismo el Cristianismo no se entiende desde verdades absolutas, sino en construcción que abarca la total dimensionalidad de la vida humana.

En el ejercicio académico de la lectura crítica de la encíclica Laudatus si de S.S. Francisco, los profesionales en formación de Contaduría plantearon algunos elementos clave para su comprensión y aplicación en su contexto inmediato. De la misma forma, el docente desarrolló algunas pistas que integran la teología con las diversas áreas del conocimiento, en aras de su mayor comprensión y descubrimiento de nuevos puntos de conexión en el espacio académico de la cátedra de Cultura Teológica. La postura inicial es que la crisis religiosa también se expresa en la actitud del ser humano frente al medio ambiente, puesto que si no hay una íntima relación con la divinidad, a lo que definimos como espiritualidad, no se manifestará un respeto absoluto hacia el otro ser viviente, que se traduce en cuidado, protección y defensa de la vida.

Desde otra perspectiva, surge la pregunta por aquel que no cree o sencillamente no es importante esa dimensión de lo religioso, y su forma de vivir y pensar el mundo es mucho más coherente que aquellos que asumen una vida de fe. En este sentido, en un contexto de cultura teológica, es importante afirmar que se acepta la postura del indiferente ante la religión, sin importar sus causas que bien pueden ser existenciales o de crítica ante las actitudes de los creyentes y ministros de las iglesias. Nuestra apuesta es por comprender que una vida de fe plenifica todas las dimensiones de la vida humana, y es coherente en su fundamento si evidencia una conducta de defensa por la vida, la justicia, el amor y el servicio. Es así que ninguna religión es digna de llamarse tal si no defiende, promueve y protege la dignidad de la persona humana, pues una experiencia con lo divino, debe llevarle a la persona humana a vivir bajo unos principios que dignifican toda expresión de vida, además que lo llevan a la protesta, crítica o profecía ante todo sistema totalitario que anule al ser humano o cualquier ser vivo (Castillo, 1978, p. 51 ss).

Es así que la reflexión giró en torno a las temáticas cruciales de la encíclica, que se enmarca dentro de lo que se define como Doctrina Social de la Iglesia, porque es la reflexión teológico-social- pastoral de la Iglesia frente a temas específicos que aluden a la realidad de la condición humana, como en este caso, la ecología y los problemas medioambientales por los que atraviesa el mundo de hoy, tema crucial y problemático que nos debe unir a todos los seres humanos 
sin importar raza, credo o ideología. Es "nuestra casa" la que está en peligro y por ello, debemos aunar esfuerzos intelectuales, materiales, políticos, sociales, económicos y culturales para salvaguardar nuestra madre tierra.

No se puede negar que la degradación del medio ambiente, el cambio climático, la deforestación de las selvas, la escasez de alimento y de agua, la violencia generalizada e institucionalizada en muchas regiones del mundo, la marcada desigualdad entre las naciones del Norte y del Sur, llevan a una calidad de vida cada vez más utópica, indigna, injusta e imposible. El Papa Francisco, aludiendo a estas problemáticas de orden global, llama la atención a la toma de conciencia por un mundo mejor, el cual es posible, si nos dejamos influir por la gracia santificante que nos une a Jesús como una verdadera comunidad de creyentes.

Nuestra fe Trinitaria en un Dios Trino, que es una comunidad unida por el amor, Dios Padre Creador, que se refleja en su Hijo Redentor de la humanidad, unidos en ese pleno amor que es el Espíritu Santo Santificador (se vale la redundancia), se inserta, libre y deliberadamente, "cayendo" en la historia humana, haciéndose una por el misterio de la Encarnación, misterio por el cual la Revelación cobra un valor sublime, pues Él como un amigo (Dei Verbum) se manifiesta a los hombres en sus propias historias, con el fin de llevarlos a la plenitud y perfección, que sólo será total al final de los tiempos. Este es el sentido de la Trascendencia, en cuanto que el hombre por su capacidad racional limitada, puede optar por comprender que su existencia tiene un sentido ulterior al que su racionalidad le permite asumir, además que su historia está inscrita en una historia de salvación, diseñada desde el mismo momento de la Creación.

El ser humano, al ser imagen de Dios, está llamado a establecer una relación íntima con Dios. En sí mismo tiene la posibilidad de experimentar los mismos sentimientos de Dios Padre, que cuida de sus creaturas, y por lo tanto, es indigno y pecaminoso el hecho que el hombre no cuide de su entorno, de sus congéneres y de su misma unión con Dios. En este sentido, ya desde el Génesis se le encomendó la tarea de cuidar su entorno, y así la naturaleza cobra un sentido mayor que el de proveedor de recursos, ya que por ella, el hombre se adhiere a su terruño, lo identifica, lo compenetra hasta sentir los mismos dinamismos que le fueron dotados; de ahí que no sea exagerado entender la naturaleza como un sacramento, pues es el signo visible del don de Dios a los hombres. Entonces, en estos tiempos actuales, es momento de resignificar nuestra espiritualidad como una unión íntima con Dios, que se traduce en actos de cuidado de sí mismo, del otro que es su igual, y del medio ambiente donde coexistimos como una comunidad viva que anhela una mayor calidad y dignidad. 
En esta unión del hombre con la naturaleza, categorías como armonía, equilibrio y renovación de todas las cosas adquieren un valor fundamental, gracias al aporte posmoderno de la importancia del sentimiento, la emoción, la imaginación y la pasión. Por eso, se puede entender lo que el Papa hablaba de "conversión ecológica", porque en los tiempos actuales el hombre necesita entender que debe volverse hacia su medio ambiente de una forma más cordial, renovar creativamente su sentido de protección, defender ante los depredadores la vida de cada ser vivo que comporta un equilibrio que posibilita la coexistencia, lo que permitirá una calidad de vida, y su fundamento último y radical está dado en que todo está en Dios.

El hombre de hoy, pensando en un futuro y el de sus próximas generaciones, debe realizar un sano y serio discernimiento acerca de su acción frente a la tecnología que, sin unos límites, puede seguir creando instrumentos de destrucción masiva; para hacer frente a la tecnocracia que plantea políticas, influenciadas por una economía vacía de humanidad y marcadas por el consumismo desenfrenado, con el fin de manipular los recursos naturales. Amén que éste es el marco de comprensión para entender tanta desigualdad e injusticia ante los más débiles y menos favorecidos del ideal modernista del progreso. Por último, este hombre debe instalarse en un momento inflexivo de crisis, de juicio ante los alcances de la globalización, pues es una necesidad potenciar sus beneficios en pro de la perfección del género humano y de la conservación de la biodiversidad planetaria.

Ahora bien, esta armonía debe vincular procesos en todas las dimensiones y en diálogo con las demás ciencias, ya que no es una opción, sino una obligación generar espacios donde surja, con solidaridad intergeneracional, una ecología integral que favorezca un desarrollo sostenible que no excluya a ningún ser humano y se le potencie en todas sus dimensiones, y que se le brinde la posibilidad de acceder plenamente a sus derechos que tiene por naturaleza; una ecología cultural que proteja el patrimonio de la humanidad, desde sus recursos naturales hasta las obras humanas que evidencia la maravilla de la mente humana; y una ecología social que propenda por una igualdad de posibilidades de acceder a los derechos que posee el ser humano, de tal forma que redunde en la experiencia de la paz.

Unido a estas metas, es importante buscar estrategias que posibiliten una economía emergente de tipo ecológico, sostenible, con la correcta valoración del sentido del trabajo, y la definición de políticas internacionales que generen impacto real, positivo e incluyente tanto del género humano como del medio ambiente. Para ello, es necesario que se establezcan lazos de diálogo abierto, serio y crítico entre las ciencias, las religiones y los saberes ancestrales de nuestras tribus aborígenes o nativas que nos recuerdan el valor de la naturaleza con su rostro divino materno. 


\section{Carta de Hans Küng (2010) y Francisco (2013)}

Con los estudiantes de Derecho se realizó una actividad consistente en hacer una lectura analítica y crítica de una Carta de Hans Küng (2010) que dirige a los obispos, en la que plantea su preocupación por la viva y patente desconfianza de los seres de este planeta por la vida y obra de la Iglesia Católica, empezando por el mismo fundamento visible que es el Papa ${ }^{4}$. Después de esta lectura, los profesionales en formación debían redactar un derecho de petición reclamando, solicitando o alegando un problema al que se vean afectados, bien como creyentes o no, ante la vida y obra de la Iglesia Católica.

Ante las condiciones planteadas por el docente, los estudiantes definieron que la urgencia de testimonio, coherencia y acercamiento a la realidad del hombre actual por parte de los ministros, profesionales de la fe, religiosos y presbíteros, es cada vez más acuciante en aras de formar una verdadera comunidad de fe. La pederastia, las noticias de corrupción en el mundo eclesial, el olvido de los profesionales de la fe de la realidad del mundo de lo humano son el cáncer que destruye el cuerpo de la comunidad de los creyentes. Ahora es muy normal que los ministros de la fe dejen a un lado los estudios teológicos y se dediquen a la formación de las comunidades, dejando ver esta ausencia de teología en las homilías y enseñanzas. Todo ello trae como consecuencia que la religión ya no sea necesaria ni haga parte esencial en la vida de los jóvenes y nuevas generaciones, porque reconocen la importancia de una espiritualidad, mas no de una filiación religiosa institucionalizada; y no se acepta lo que Castillo establece de la innegable configuración como institución de la religión (2012, p. 47).

Ante este reclamo en silencio y mucho más perjudicial para la "vida interna" de la sociedad, se necesita expresar de modos más adecuados el hablar de Dios y prestar atención a las imágenes sobre Dios. Juan José Tamayo (2004) establece que la imagen o símbolo sobre Dios es el fundamento de todo sistema religioso y referente en la comprensión del mundo, de la historia, de la vida humana; además que le da identidad a las comunidades, determina su orientación vital y su comportamiento. Por eso afirma, este importante autor, con gran claridad y lectura crítica de la realidad:

4 En el tiempo de esta carta, Benedicto XVI era el sumo pontífice, del que Hans Küng anota que fueron compañeros de la Universidad de Tubinga y los peritos más jóvenes del Concilio Vaticano II, y que ahora en su etapa de pontificado ha vuelto a ciertas prácticas litúrgicas y políticas teológicas que recuerdan la vida eclesial medieval, lo que ha abierto aún más el abismo con las religiones no cristianas que poseen una misma raíz. 
Un Dios dictador como el adorado por el general Pinochet genera prácticas violentas. Un Dios liberador como el de los mártires Ignacio Ellacuría y monseñor Romero genera actitudes de paz y perdón, de reconciliación y hermandad. Un Dios vengativo como el de Bin Laden provoca actitudes de venganza y aplicación de la ley del talión entre sus seguidores. Un Dios del "pueblo elegido" como el de George Bush genera actitudes de exclusión para con otros pueblos y las minorías. Un Dios pacífico como el de Martin Luther King activa una lucha no violenta a favor de la igualdad y de la no discriminación (Tamayo-Acosta, 2004, p. 17).

En este particular de las imágenes sobre Dios, los estudiantes de Derecho, por su misma perspectiva profesional, criticaron la imagen del poder, resaltando que la institución Iglesia es símbolo de poder monárquico absoluto proveniente de Roma, ya que las demás conferencias episcopales no se comprometen con el gobierno colegiado, el cual es la verdadera fuente de autoridad eclesial. También evidencian la poca importancia o relevancia que poseen los presbíteros y obispos en la vida cotidiana de los jóvenes. De ahí que rescataran las palabras "poder en relación" que "hace a los seres humanos partícipes del poder de la vida y lo convierte no en Dios-sobre-nosotros, sino en Dios-en-nosotros" (Tamayo-Acosta, 2004 , p. 20). Entonces, la fe en una realidad cada vez más humana, esto es, asumida desde los mismos horizontes de comprensión humanos -lo que no quiere decir con los anhelos e intereses limitados del hombre- será la única forma de no convertir la religión, y en este caso particular, el cristianismo en todas sus versiones y confesiones, en una ideología alienante y vacía de los valores que predicó el mismo Jesús, el Cristo.

En las discusiones con los estudiantes de Derecho y Contaduría se fueron obteniendo algunas conclusiones acerca del texto del Papa Francisco (2013) a un ateo, en las que se resaltaron que la fe no es superstición sino adhesión personal, existencial y libre a Dios, la cual da plenitud de sentido al ser humano creyente. Se puede tildar de oscuridad, la comprensión epistemológica de la racionalidad instrumental que define la realidad como el único criterio de veracidad, heredera de la modernidad; en cambio, en la actualidad, se deben establecer espacios de diálogo de la teología, la religión con las demás ciencias (Francisco, 2013, p.1).

En el momento de la verdad y la fe, que Scalfari le plantea al Papa, ésta es un lente por el que se ve y entiende la realidad, y el creyente la "pone" en diálogo con las demás cosmovisiones y perspectivas para construir una sociedad más 
humana y con calidad de vida (2013, p.2). Todo mediado por la experiencia originaria con Jesús que llega al encuentro con el ser humano, lo que hace que la fe sea un hecho histórico que transformó la vida de los apóstoles, y de la que nosotros también vivimos, porque la hemos experimentado y aprendido a lo largo de la tradición. Así pues, tiene un doble camino: la historia y la experiencia humana. Esta es la originalidad de la fe cristiana, la transdescendencia, en términos de Boff (2012, p.75), la cual indica que la acción salvífica divina se traduce en términos de que la trascendencia absoluta se encarna en la historia humana, haciéndose una con ella, y la cual se expresa a través de una vida transparente en relación con el mensaje y la coherencia de vida.

Entonces, la apuesta por una vida cristiana tiene sentido cuando no se aleja del mundo ni busca un poder absoluto, sino todo lo contrario; es decir, en palabras de Francisco: "servicio al hombre, al hombre todo y a todos los hombres, a partir de la periferia de la historia manteniendo siempre vivo el sentido de la esperanza que incita a obrar el bien no obstante todo y mirando siempre más allá" (2013, p. 4); el fundamento teológico, por tanto, es histórico y existencial de una experiencia, en la que el pueblo de Israel es el pueblo de la espera en una promesa, fundada en la alianza que hizo Yahveh con su pueblo, y que el Cristianismo asume que está cumplida en la persona de Jesús. Las categorías pueblo, alianza, fe, tierra, promesa, mesías, ley y Dios, determinan el horizonte de comprensión del Judaísmo y su relación con el Cristianismo, que es la plenitud de las mismas, pero es un don y tarea que cada creyente debe cumplir y llevar a cabo en todo acto cotidiano; por tanto, es misión de cada cristiano manifestar en su vida el mensaje del Reino que es vivir bajo los preceptos de justicia, libertad, amor, servicio, equidad y dignidad.

Por último, es importante reconocer que los estudiantes hacen suyas las palabras, pensamiento y actitud del gran teólogo Hans Küng (2010) quien, a pesar de su historia con el magisterio romano, le habla con misericordia, inteligencia, profecía y parresía, a todos los obispos. Que ellos ante la comunidad de creyentes, no deben callar ante las irregularidades y pecados de sus profesionales de la fe, sino todo lo contrario, vivir en profecía (anuncio y denuncio); asumir el papel que se les ha dado desde el gobierno colegiado, esencia de la autoridad de la Iglesia, de tal forma que tenga una apertura a las necesidades del mundo real de los fieles y no tan fieles. Ante todo, vivir bajo el Espíritu del Evangelio y su mensaje, hacer una lectura contextual de los derechos humanos en clave de diálogo interreligioso para buscar la experiencia de la paz 


\section{Referencias bibliográficas}

Alfaro, Juan (1978). Preámbulos de la fe. En Sacramentum Mundi III (pp. 104-106) Barcelona, España: Herder.

Beck, U (12/01/2008). Dios es peligroso. El País. Madrid; España.

(2009). El dios personal. La individuación de la religión y el espíritu del cosmopolitismo. Barcelona, España: Paidós.

Boff, Leonardo (2002). Tiempo de Trascendencia, el ser humano como un proyecto infinito. 2a . Edición. Santander, España: Sal Terrae.

Castillo, José María (2012). La humanidad de Dios. Madrid, España: Trotta.

(1978). La alternativa cristiana. Hacia una iglesia del pueblo. Ediciones. Salamanca, España: Sígueme.

Cullman, Oscar (1948). Le culte dans l’eglise primitive. París, Francia: Neuchatel.

Dei Verbum (1966). En ConcilioVaticano II. Madrid, España: BAC

SS. Francisco (2013). Carta a un ateo. Recuperado de: http://www.repubblica.it/cultura/2013/09/11/news/papa_francisco_escribe_a_repubblica_dilogo_abierto_con_ los_no_creyentes-66346803/

Hernández A., Alvaro (2016). Reflexiones teológicas en clase. Universidad Santo Tomás, Tunja.

Küng, Hans (2010). Carta abierta a los obispos. Recuperado de: http://aristeguinoticias. com/1102/mundo/documento-carta-de-hans-kung-a-obispos-del-mundo-antecrisis-de-credibilidad-de-la-iglesia/

Latourelle, Rene (1966). Teología de la Revelación. Salamanca, España: Sígueme.

López M., Milton D. (2015). Proponer la fe cristiana en una cultura de indiferencia religiosa e increencia. Tesis para obtención de grado. Disponible en: http://repository.javeriana.edu.co/bitstream/10554/16996/1/LopezMoraMiltonDavid2015.pdf

Lumen Gentium (1966). En: Concilio Vaticano II. Madrid, España: BAC

Poupard, Paul (s/f). La cultura de la indiferencia religiosa. Recuperado de:

http://es.catholic.net/op/articulos/19591/cat/1105/la-cultura-de-la-indiferencia-religiosa.html

S.S. Francisco (2015). Laudatus si. Roma, Italia: Editorial Vaticana.

Velasco, Juan Martín (2010). ¿Crisis de Dios en la Europa de tradición cristiana? En: Tirant lo Blanch-G. J. Chamina-de. La fe perpleja. ¿Qué creer? ¿Qué decir?, Valencia, España: Trotta.

Tamayo-Acosta, Juan José (2004). Nuevo paradigma teológico. Madrid, España: Trotta.

Vian Herrero, Ana (2009). El indio dividido. Fracturas de conciencia en el Perú colonial. Madrid, España: Iberoamericana-Vervuert. 